\title{
Designed modular proteins as scaffolds to stabilize fluorescent nanoclusters
}

Pierre Couleaud, ${ }^{a b+}$ Sergio Adan-Bermudez, ${ }^{a+}$ Antonio Aires, ${ }^{a}$ Sara H. Mejías, ${ }^{a b}$ Begoña Sot, ${ }^{a b}$ Alvaro Somoza, ${ }^{a b^{*}}$ and Aitziber L. Cortajarena. ${ }^{a b^{*}}$

${ }^{a}$ IMDEA-Nanociencia, Campus de Cantoblanco, 28049 Madrid, Spain.

${ }^{b}$ Centro Nacional de Biotecnología (CNB-CSIC) - IMDEA Nanociencia Associated Unit, Campus de Cantoblanco, 28049 Madrid, Spain.

\section{Sequences of CTPR protein variants}

CTPR3 (C3):

GAMDPGNSAEAWYNLGNAYYKQGDYDEAIEYYQKALELDPNNAEAWYNLG NAYYKQGDYDEAIEYYQKALELDPNNAEAWYNLGNAYYKQGDYDEAIEYYQ KALELDPNNAEAKQNLGNAKQKQG

Molecular weight: 14360.3

CTPR3-Cys (C3-Cys):

GAMDPGNSAEAWYNLGNAYYKQGDYDEAIEYYQKALELDPNNAEAWYNLG NAYYKQGDYDEAIEYYQKALELDPNNAEAWYNLGNAYYKQGDYDEAIEYYQ KALELDPNNAEAKQNLGNAKQKQGC

Molecular weight: 14463.4

CTPR3-90 (C3-90):

GAMDPGNSAEAWKNLGNAYYKQGDYQKAIEYYQKALELDPNNASAWYNLG NAYYKQGDYQKAIEYYQKALELDPNNAKAWYRRGNAYYKQGDYQKAIEDY QKALELDPNNAKAKQNLGNAKQKQG

Molecular weight: 14354.7 
CTPR3-Cys-90 (C3-Cys-90):

GAMDPGNSAEAWKNLGNAYYKQGDYQKAIEYYQKALELDPNNASAWYNLG NAYYKQGDYQKAIEYYQKALELDPNNAKAWYRRGNAYYKQGDYQKAIEDY QKALELDPNNAKAKQNLGNAKQKQGC

Molecular weight: 14457.8

\section{Characterization CTPR-stabilized AuNCs}

\subsection{Synthesis under basic conditions $(\mathrm{NaOH})$}

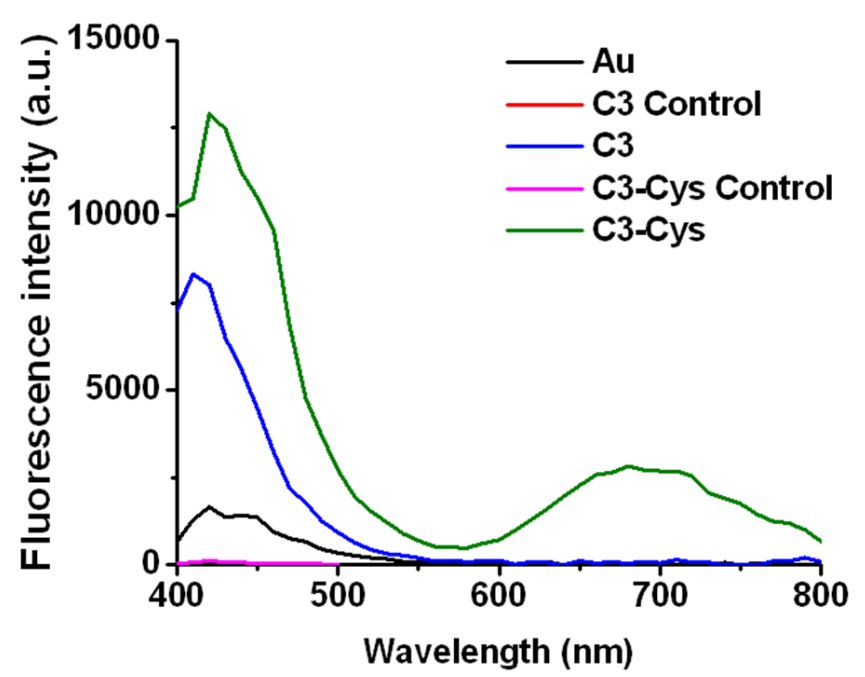

Figure S1. Fluorescence emission spectra of AuNCs samples formed in basic conditions $(\mathrm{NaOH})$ stabilized by $\mathrm{C} 3$ (blue line) and C3-Cys (green line). The control reactions performed in basic conditions $(\mathrm{NaOH})$ with $\mathrm{C} 3$ protein without $\mathrm{Au}$ salts $(\mathrm{C} 3$ Control, red line), C3-Cys without Au salts (C3-Cys Control, pink line) and Au salts without any CTPR protein (Au, black line). 


\subsection{Synthesis under mild conditions (Ascorbic acid)}

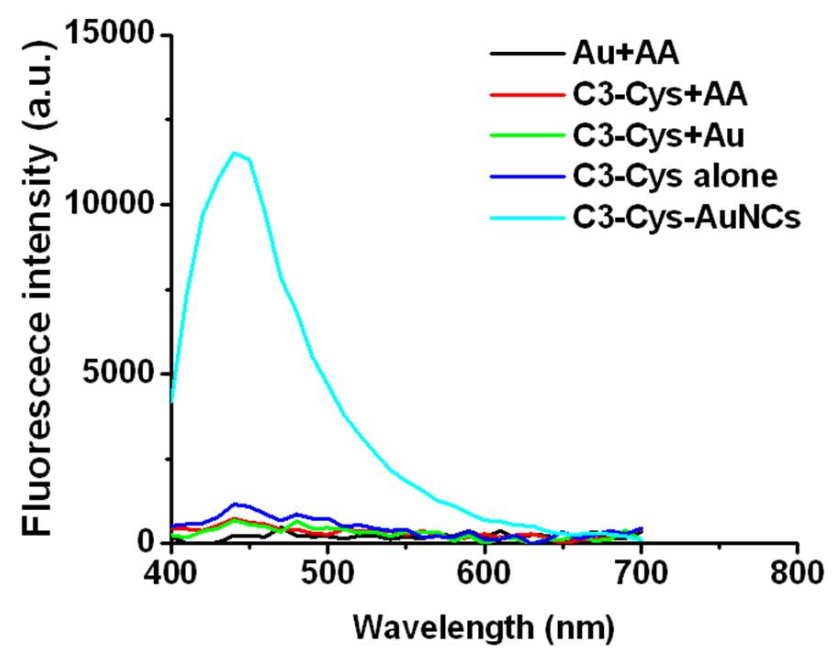

Figure S2. Fluorescence emission spectra of the reduction reactions with ascorbic acid. $\mathrm{HAuCl}_{4}$ with ascorbic acid ( $\mathrm{Au}+\mathrm{AA}$, black line), C3-Cys protein without $\mathrm{Au}$ salts and ascorbic acid (C3-Cys alone, dark blue line), C3-Cys in the presence of ascorbic acid without $\mathrm{Au}$ salts (C3-Cys+AA, red line), $\mathrm{C} 3-\mathrm{Cys}$ in the presence of $\mathrm{HAuCl}_{4}$ without ascorbic acid (C3-Cys+Au, green line), and the complete reaction $\mathrm{C} 3-\mathrm{Cys}-\mathrm{AuNCs}$ (cyan line).

\subsubsection{Mass spectrometry analysis of C3-Cys-AuNCs sample}

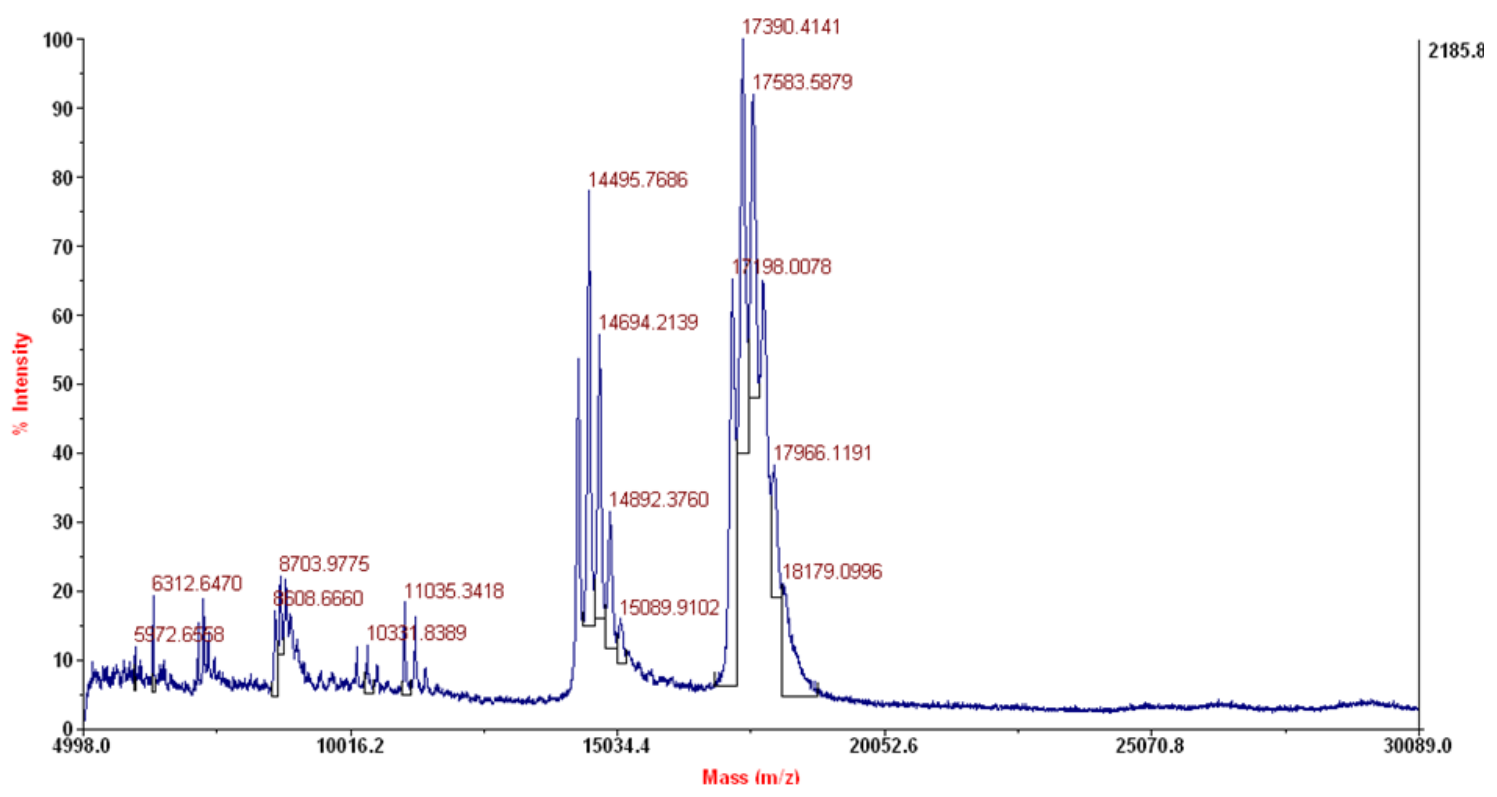

Figure S3. MALDI-TOF mass spectrum of C3-Cys-AuNCs shows two main peaks, corresponding to C3-Cys protein $(\mathrm{m} / \mathrm{z} 14496)$ and C3-Cys-AuNCs $(\mathrm{m} / \mathrm{z} 17390)$. 


\subsection{Synthesis of C3-Cys-90-AuNCs with ascorbic acid}

The fluorescence emission and MALDI-TOF spectra of the C3-Cys-90-AuNCs show that we obtained fluorescent C3-Cys-90-AuNCs comparable to the clusters obtained for C3-Cys using ascorbic acid as mild reducing agent.
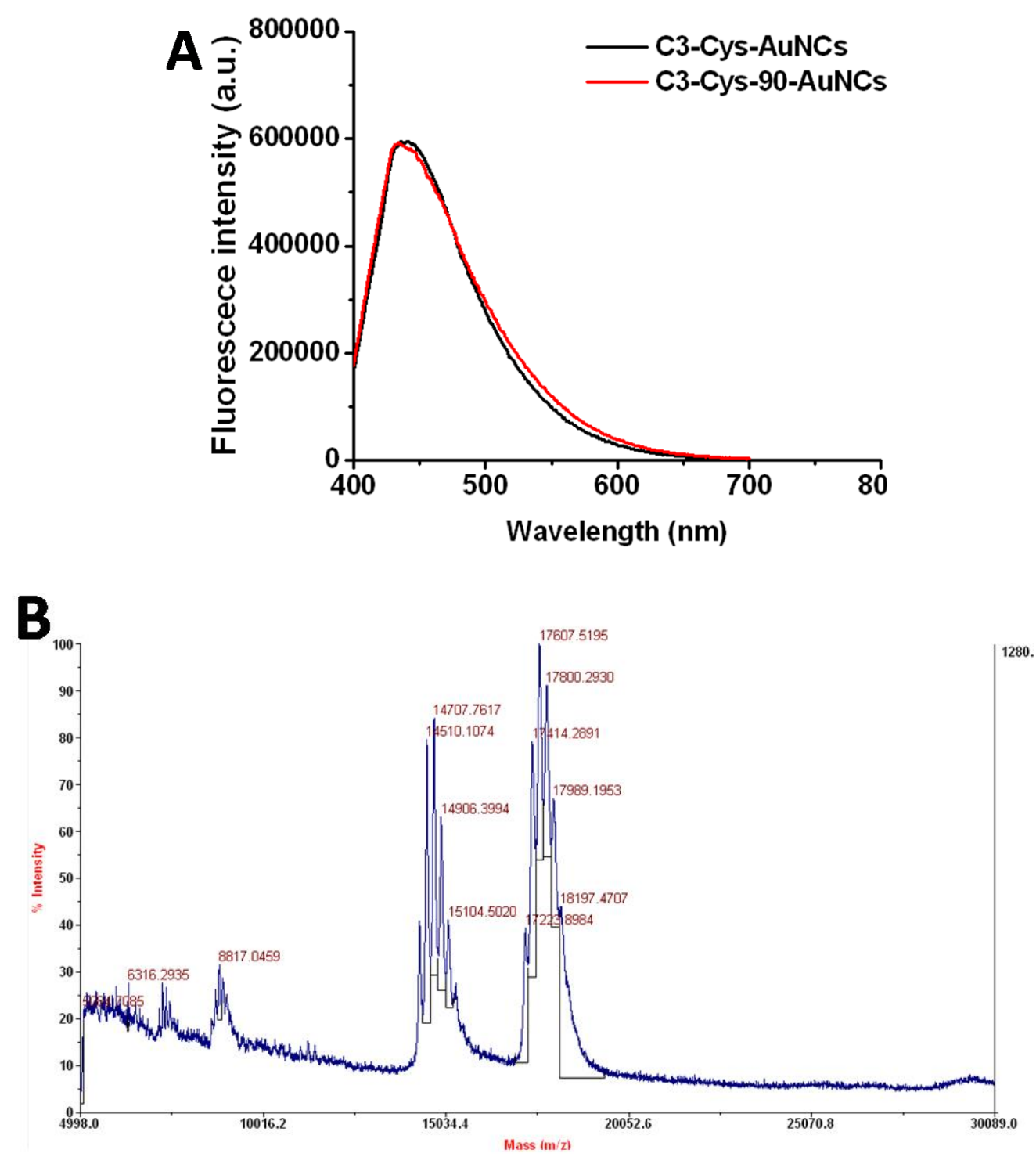

Figure S4. (A) Fluorescence emission spectra C3-Cys-AuNCs (black line) and C3-Cys90-AuNCs (red line) reduced by ascorbic acid. (B) MALDI-TOF mass spectrum of C3Cys-90-AuNCs shows two main peaks corresponding to C3-Cys-90 protein $(\mathrm{m} / \mathrm{z}, 14708)$ and C3-Cys-90-Au ${ }_{14} \mathrm{NCs}(\mathrm{m} / \mathrm{z}, 17608)$. 


\section{Characterization of C3-Cys-90-AuNCs based sensor}

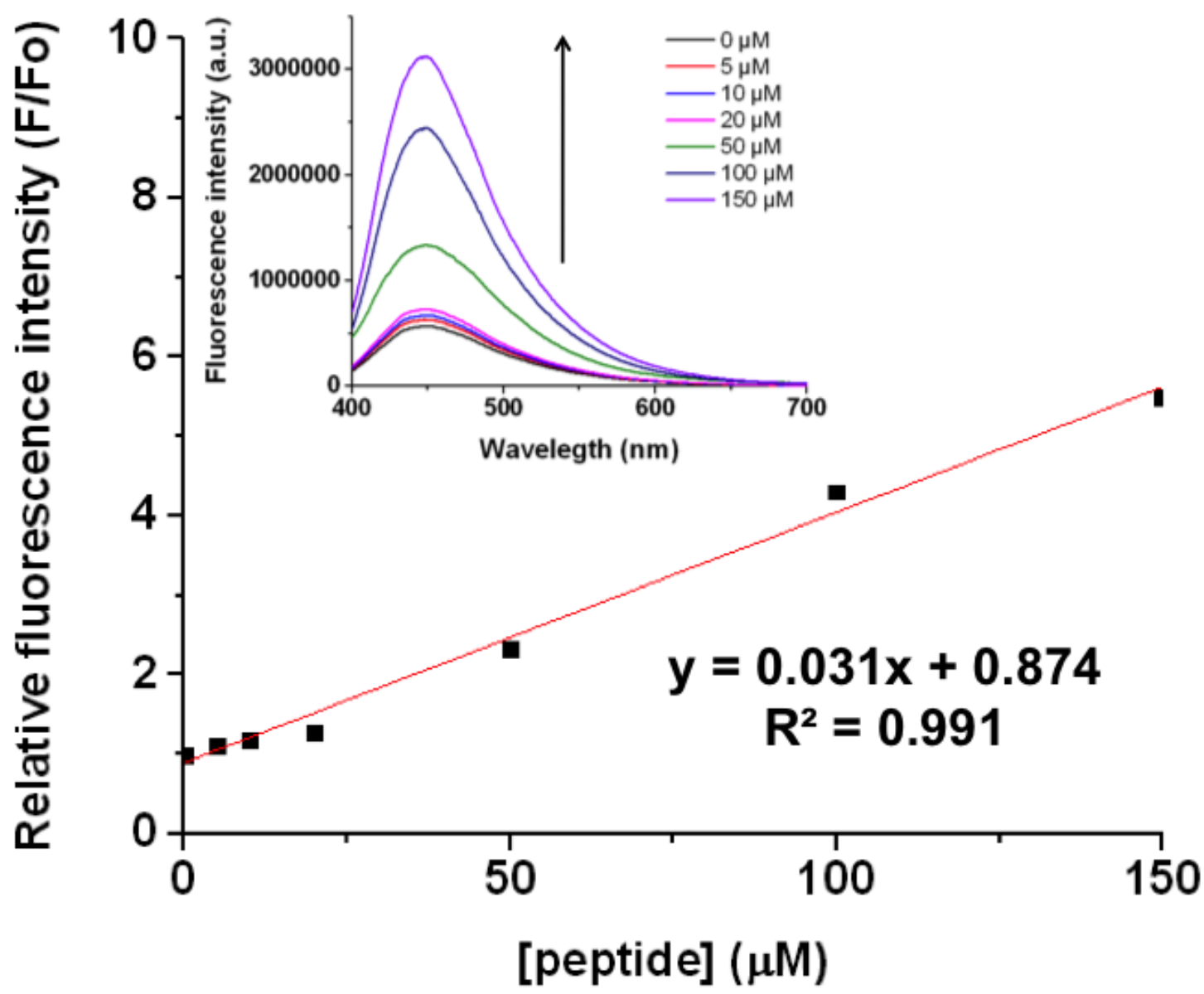

Figure S5. Sensing properties of C3-Cys-90-AuNCs complex. Change in the fluorescence emission intensity of the AuNCs from C3-Cys-90-AuNCs complex upon the addition of increasing concentrations of Hsp90 peptide (black squares). The linear regression fit in the range of $5-150 \mu \mathrm{M}$ Hsp90 peptide concentration is shown as a red line. LOD and LOQ parameters are calculated from the linear regression parameters. The inset shows the change in the fluorescence emission spectra of the C3-Cys-90AuNCs complex upon addition of increasing concentrations of Hsp90 peptide. 